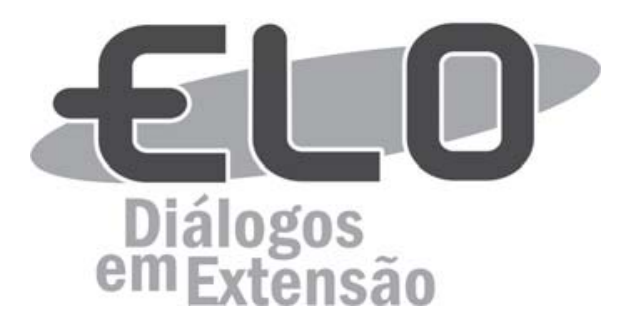

\title{
Gestão de Custos no Terceiro Setor: aplicação na Instituição de Longa Permanência de Idosos de Rio Paranaiba/MG
}

\author{
Lucas Alexandre Rocha ${ }^{1}$, Rodrigo Silva Diniz Leroy ${ }^{2}$, \\ Maycon Henrique Marques ${ }^{3}$, Edson Rodrigo de Almeida ${ }^{4}$
}

\begin{abstract}
Resumo: O Terceiro Setor possui significativa importância na sociedade em função dos serviços prestados, sendo suas atividades e sustentabilidade financeira desejáveis para a sociedade. Dessa forma, a presente pesquisa analisou a estrutura de custos com base nas informações gerenciais da Instituição de Longa Permanência de Idosos (ILPI) do município de Rio Paranaíba/MG. O estudo foi do tipo qualitativo, sendo resultado de uma pesquisa ação realizada em uma Casa de Repouso no ano de 2018. Com base na Resolução 283/2005 da ANVISA para divisão em classes dos internos, o estudo resultou no custo de $R \$ 6.830,22$ para incapazes, $R \$$ $3.569,63$ para dependentes e $R \$ 3.173,79$ para independentes, valores por trimestre. Os resultados possibilitaram à entidade maior conhecimento gerencial para a análise de admissões, tomada de decisões e na busca de novas fontes de recursos, visando a longevidade dos serviços, bem como o bem-estar social.
\end{abstract}

Palavras-chave: Extensão. Gestão de Custos. Instituição de Longa Permanência de Idosos.

Área Temática: Educação. Direitos humanos.

\section{Cost Management in the Third Sector: application in the long-term care institution of Rio Paranaiba/MG}

\begin{abstract}
The Third Sector has significant importance in society due to the services it provides, and its activities and financial sustainability are desirable for society. In this way, the present research analyzed the cost structure based on the management information of the long-term care institution of the city of Rio Paranaiba/ MG. The study was of the qualitative type, being the result of an action research carried out in a Nursing Home in the year 2018. Based on ANVISA Resolution 283/2005 for division into classes of inmates, the study resulted in a cost of $R \$ 6,830,22$ for the disabled, $R \$ 3,569.63$ for dependents and $R \$ 3,173.79$ for independents, values per quarter. The results allowed the entity greater managerial knowledge for the analysis of admissions, decision making and the search for new sources of resources, aiming at the longevity of services, as well as social welfare.
\end{abstract}

Keywords: University Extension. Costs management. Rest Home.

\section{Gestión de Costos en el Tercer Sector: aplicación en la casa de reposo de Rio Paranaiba/MG}

Resumen: El tercer sector tiene una significativa importancia en la sociedad debido a los servicios prestados por él, siendo sus actividades y sostenibilidad financiera deseables para la sociedad. De esta forma, la presente investigación analizó la estructura de costos con base en las informaciones gerenciales de la casa de reposo del municipio de Rio Paranaíba/MG. El estudio fue del tipo cualitativo, siendo el

${ }^{1}$ In memoriam - Graduado em Ciências Contábeis pela Universidade Federal de Viçosa (UFV), Rio Paranaíba, MG, Brasil.

${ }^{2}$ Professor do curso de Ciências Contábeis da Universidade Federal de Viçosa (UFV), Rio Paranaíba, MG, Brasil (rodrigo.leroy@ufv.br).

${ }^{3}$ Graduado em Ciências Contábeis pela Universidade Federal de Viçosa (UFV), Rio Paranaíba, MG, Brasil.

${ }^{4}$ Professor do curso de Ciências Contábeis da Universidade Federal de Viçosa (UFV), Rio Paranaíba, MG, Brasil. 
resultado de una investigación de acción realizada en una Casa de Descanso en el año 2018. Con base en la Resolución 283/2005 de la ANVISA para división en clases de los internos, el estudio resultó en el costo de $R \$ 6.830,22$ para incapacidades, $R \$ 3.569,63$ para dependientes y $R \$ 3.173,79$ para independientes, valores por trimestre. Los resultados posibilitar a la entidad mayor conocimiento gerencial para el análisis de admisiones, toma de decisiones y en la búsqueda de nuevas fuentes de recursos, visando la longevidad de los servicios, así como el bienestar social.

Palabras clave: Tercer Sector. Gestión de costos. ILPI. Extensión Universitaria.

\section{Introdução}

O Brasil passa por uma mudança na pirâmide etária, isto acontece devido aos índices de fecundidade e mortalidade estarem em queda e, por conta disso, a população idosa do país aumenta (cf. IBGE, 2015). As Organizações do Terceiro Setor (OTS) têm atuado como alternativa para melhorar a qualidade de vida dos idosos. Tendo a necessidade de atuar frente à lacuna deixada pelo Estado (Primeiro Setor), o qual não consegue atender a demanda, abrindo espaço para entidades sem fins lucrativos.

Dessa forma, visando as suas funções sociais, sua atuação junto ao governo e à sociedade, e sabendo que esses são os principais mantenedores dessas organizações (através de doações, subsídios, transferências, entre outros), as entidades do terceiro setor devem se atentar sempre para a transparência das informações prestadas, utilizando-se, para a divulgação de informações confiáveis, tempestivas e claras, de mecanismos disponibilizados pela contabilidade (PAULA; MÁRIO, 2011).

Entretanto, por não terem finalidade lucrativa, algumas OTS passam por dificuldades financeiras, dado que por vezes possuem recursos escassos, o que as obriga a ter uma gestão eficiente e eficaz (cf. PEREIRA et al., 2013b; SANTOS, LAUREANO, MACHADO, 2014; TOZZI, 2014). Quando se compreende a relevância destas entidades perante a sociedade, conjugado ao fato do interesse pela continuidade de suas atividades, desperta-se para a necessidade de uma boa gestão financeira. Assim, mensurar os custos incorridos por estas instituições pode ser um caminho inicial para auxiliar no processo de gestão dos recursos, pela possibilidade de esclarecimento da destinação dos valores incorridos e melhoria na administração dessas entidades.

Tendo em vista que essas entidades abrangem tamanha diversidade de interesses e ainda atuam nas mais diversas áreas (como saúde, educação, cultura, esporte, entre outros), Soares e Melo (2009) ressaltam que uma das principais dificuldades generalizadas, como das ONGs, por exemplo, é "desenvolver uma estrutura de gestão adequada às peculiaridades com as seguintes características: flexibilidade, criatividade e sensibilidade" (SOARES; MELO, 2009, p. 2).

Além disso, por vezes é difícil para as entidades filantrópicas a contratação de um colaborador para atuar no gerenciamento e que utilize métodos e instrumentos adequados para obtenção de bons resultados (MÁRIO et al., 2013). Soares e Melo (2009) explicitam que, como ocorre com algumas sociedades anônimas, muitas das entidades sem fins lucrativos não possuem suporte técnico suficiente e mão de obra capacitada para encontrar as maneiras mais eficientes de desenvolverem os métodos gerenciais adequados às suas especificidades.

Nesse contexto, e sabendo da necessidade de um sistema próprio, muitas vezes personalizado, se insere a interação entre as organizações e a universidade, através dos projetos de extensão universitária, que figuram como instrumento de suporte para a comunidade, nas mais diversas formas e áreas. Sendo assim, emerge a possibilidade de fornecer apoio às organizações do terceiro setor por meio de projetos de extensão, principalmente no que tange às práticas gerenciais (MÁRIO et al., 2013). A atividade extensionista pode viabilizar o desenvolvimento de ferramentas gerenciais, desenvolvidas especificamente para a realidade de cada organização, de modo que as entidades não lucrativas disponham de infraestrutura e capacitação gerencial voltada para suas especificidades, garantindo a interação entre o conhecimento adquirido nas universidades e as necessidades práticas deste mercado, cumprindo assim com o papel social da extensão universitária.

Deste modo, para tentar colaborar com a solução de tal problema de gestão identificado previamente, foi realizada uma ação de extensão universitária intitulada "Assessoria financeira e gerencial a entidades filantrópicas de Rio Paranaíba/MG", aplicada na Instituições de Longa Permanência de Idosos (ILPI) do município, a "Casa de Repouso Confrade Antônio do Carmo Pimenta". As ILPIs são um dos campos de atuação das OTS sem fins lucrativos, que atua na assistência social de 
idosos e garante moradia, vestuário, medicamentos, cuidados médicos, entre outras benfeitorias que melhoram sua qualidade de vida (IBGE, 2015).

Portanto, considerando a intervenção extensionista de assessoria financeira e gerencial realizada na entidade, conjugada à necessidade de melhorias na administração das OTS, o presente estudo tem a seguinte problemática de pesquisa: como se dá a estrutura de custos da ILPI e quais as aplicações financeiras e gerenciais da admissão de um interno na instituição?

Desta forma, o objetivo dessa pesquisa foi analisar e propor uma estrutura de custos com base nas informações gerenciais da ILPI do município de Rio Paranaíba/MG. Esta ILPI presta assistência a 41 idosos, tendo como principal fonte de receitas os aposentos dos internos. Foram analisadas as movimentações financeiras ocorridas no $1^{\circ}$ trimestre do ano de 2018 , sendo verificada a situação da instituição para proposição de melhorias de práticas de gestão, bem como propor uma estrutura de custos e suas implicações na tomada de decisão.

Assim, a contribuição deste estudo consiste em auxiliar a entidade em sua gestão financeira, evidenciando os resultados da efetiva prática extensionista da Universidade para com a sociedade, além de contribuir para a literatura, que é escassa no que se refere à gestão financeira e controle de custos do Terceiro Setor.

\section{Referencial Teórico}

\section{Terceiro setor e Instituição de Longa Permanência de Idosos (ILPI)}

No Brasil, as primeiras atuações do Terceiro Setor se deram nos anos 1970 na forma de reação contra o regime autoritário da ditadura e em busca da democracia, se dando o fortalecimento desse setor em contrapartida a uma fragilidade nos laços com o Estado. Porém, somente por volta do final da década de 1980 e início dos anos 1990, teve início a utilização do termo Terceiro Setor, sendo este uma mistura de entidades privadas com finalidade pública, de atendimento à necessidade social, por vias alternativas ao Estado (SANTOS, 2012).

O terceiro setor é constituído por organizações privadas, sem fins lucrativos, que geram bens e serviços com o objetivo de desenvolvimento político, econômico, social e cultural no meio em que atuam (SANTOS, 2010). De acordo com Santos (2010, p. 22), "as organizações sem fins lucrativos são organizações não governamentais que apresentam objetivos sociais, filantrópicos, culturais, recreativos, religiosos e artísticos".

Assim, o Terceiro Setor resulta de diversas mobilizações que contribuíram para a criação de organizações que contrapõem o modelo atual de gestão governamental e o desenvolvimento de políticas públicas, constituindo um setor específico, que vem se destacando, e atualmente é fundamental para o equilíbrio social (PEREIRA et al., 2013a). Com isso, percebe-se que as Organizações do Terceiro Setor (OTS) possuem importante papel na sociedade ao suprir lacunas sociais deixadas pelo Estado.

As OTS's possuem diversos campos de atuação, como por exemplo, educação, saúde e assistência social. Segundo dados do IBGE (2015), existem 13.659 Unidades de Prestação de Serviços Socioassistenciais, composto por um conjunto de lares, orfanatos, albergues, asilos, centros de reabilitação, obras sociais diversas, casas de passagem, casas de acolhida, clubes de mães, grupos de apoio, núcleos de orientação, círculos de amigos, entre outras diferentes iniciativas sociais.

Dentre as organizações sem fins lucrativos de assistência social, destacam-se aquelas destinadas a acolhimento e atendimento aos idosos, que vêm se tornando mais comuns, o que pode ser explicado devido ao aumento da expectativa de vida da população. Para o IBGE (2015), a diminuição da mortalidade e aumento da fecundidade influenciam na inversão da pirâmide etária brasileira, havendo assim, uma tendência na elevação da população idosa. Verificou-se ainda que unidades para idosos, nomeadas na Tipificação Nacional de Serviços Socioassistenciais como casa-lar, abrigo institucional ou instituições de longa permanência para idosos, representam $65,5 \%$ das unidades de acolhimento.

Quanto às Instituições de Longa Permanência para Idosos (ILPIs), segundo Camarano e Kanso (2010, p. 233), "sua origem está ligada aos asilos, inicialmente dirigidos à população carente que necessitava de abrigo, frutos da caridade cristã diante da ausência de políticas públicas". Conforme a Resolução ANVISA n 283 de 26 de setembro de 2005, as ILPIs são "instituições governamentais ou não governamentais, de caráter residencial, destinada a domicílio coletivo de pessoas com idade igual ou superior a 60 anos, com ou sem suporte familiar, em condição de liberdade e dignidade e cidadania". 
Essas instituições têm como desafios inerentes os cuidados com a saúde dos internos, que enfrentam problemas como depressão, a cognição e a capacidade funcional (MEDEIROS et al., 2016), além das questões psicológicas provenientes do avanço da idade e do distanciamento dos familiares, fatores que afetam negativamente o bem-estar dos idosos (SANTOS et al., 2014).

Ademais, conjugado a esses desafios, em muitas situações as ILPIs apresentam problemas na gestão, deixando-as distantes do padrão de qualidade definido em legislação como desejável para o bom atendimento às necessidades dos internos (LIMA POLLO;ASSIS, 2008). Essas dificuldades na gestão podem ter significativa influência dos problemas financeiros enfrentados por esse tipo de entidade, visto que a escassez de recurso, conjugada à sua alocação inadequada, pode implicar em problemas no atendimento adequado dos idosos.

\section{Gestão financeira em Organizações do Terceiro Setor (OTS)}

As OTS possuem um diferencial perante os outros tipos de organizações, uma vez que não visam lucro, mas necessitam de uma eficiente gestão de recursos para sua sustentabilidade. As entidades filantrópicas necessitam de apresentar eficiência e eficácia na gestão de seus recursos financeiros e operacionais, apesar de não terem a finalidade de lucro (VOESE; REPTCZUK, 2011). Para tanto, a promoção dessa boa gestão dos recursos pode ter o auxílio de assessoramento financeiro, gerencial e contábil, o que propiciaria amparo à continuidade de suas ações.

No entanto, existem diversos desafios na gestão das OTS, relacionados às funções planejamento, organizações, direção e controle, havendo, no caso das instituições brasileiras, dificuldades adicionais relacionadas ao seu financiamento, por geralmente dependerem de verbas governamentais e doações, e à avaliação de seus resultados, devido à carência de indicadores e de registros sistemáticos dos dados (TENÓRIO, 2009).

A função de gestão contábil se encontra deficitária, uma vez que é encarada pelo setor como uma obrigação desagradável, cuja maior contribuição seja a indicação da necessidade de pagamento de tributos (PEREIRA et al., 2013b). O fato da exigência de conhecimento técnico específico dos gestores e muitas vezes por parte do contador, para a utilização de relatórios e tecnologias contábeis como instrumento de gestão, não sendo apenas utilizados aspectos fiscais, contribuem para essa realidade. Assim, os autores do presente artigo destacam que para gerir essas entidades é necessário mais que apenas boas intenções, mas certo nível conhecimento técnico.

A ausência de planejamento estratégico e gestão integrada, aliados à ausência de sistemas de custos adequados para fins gerenciais, tornam a ação e o processo das entidades sem fins lucrativos uma atividade de "sorte" e muita dependência de fatores externos, podendo ser prejudicial para sua continuidade (MÁRIO et al., 2013). A inserção de modelos adequados a estas entidades e suas realidades, acompanhados de treinamento de seus dirigentes, podem resultar na minimização desse contexto, juntamente com maior profissionalismo na gestão.

As ILPIs, destacadamente, percebem mais resultados com a gestão financeira e custos pois, as mesmas operam normalmente com recursos escassos e em contrapartida com despesas altas. Com isso, Roquete, Batista e Arantes (2017, p. 298) afirmam que "para desempenhar sua função com qualidade e efetividade, as ILPI necessitam profissionalizar o gerenciamento, tendo em vista o fato de contarem com recursos, em geral, escassos". Além disso, os autores reforçam que pelo fato destas instituições atenderem idosos, seus custos tendem a ser elevados, sendo necessárias várias fontes de receitas.

Para isso, o fluxo de caixa é uma ferramenta que pode auxiliar na gestão desses recursos. Ele tem a função de quantificar o descompasso entre entrada e saída de recursos para que os gestores possam tomar decisões, com o que fazer com sobras ou falta de recursos (TOZZI, 2014). Percebe-se assim que um dos instrumentos mais utilizados para o controle financeiro no terceiro setor é o fluxo de caixa, dado que por meio dele é possível ter a percepção de entrada e saída de recursos, logo essa se configura como ferramenta de importante auxílio para a gestão.

\section{Contabilidade de Custos}

A Contabilidade Gerencial e a de Custos estão intimamente ligadas, uma vez que a Contabilidade de Custos fornece informações relevantes, quanto aos produtos e serviços oferecidos por uma determinada organização, as quais poderão subsidiar a tomada de decisão. Nesse sentido, "a 
Contabilidade de Custos tem duas funções relevantes: o auxílio ao Controle e a ajuda às tomadas de decisões." (MARTINS, 2010, p. 21)

A contabilidade de custos pode ser definida como um conjunto de procedimentos que são alocados para a determinação do custo de um produto, assim como, das várias atividades ligadas a ele, além de auxiliar o planejamento e mensuração de desempenho (LEONE, 2008). Além disso, é o ramo da função financeira que coleta, acumula, organiza, analisa, interpreta e informa os custos dos produtos e dos serviços, afim de determinar a rentabilidade e avaliar o patrimônio da empresa, para controlar os próprios custos, além de auxiliar o planejamento e a tomada de decisão (LEONE, 2008).

Martins (2010, p. 25) define que custo é "gasto relativo a bem ou serviço utilizado na fabricação de outros bens e serviços". Os custos também podem ser classificados de diversas formas, no entanto, para fins de resumo segregam-se em custos diretos, indiretos, fixos e variáveis. O custo direto é aquele naturalmente identificado ao objeto de custeio (LEONE, 2008), ou seja, é aquele facilmente alocado ao produto ou a prestação de serviço. Já o indireto tem comportamento oposto e que, segundo Martins (2003, p. 33) são os que "não oferecem condição de uma medida objetiva e qualquer tentativa de alocação tem de ser feita de maneira estimada e muitas vezes arbitrária".

Os custos fixos se caracterizam como aqueles que permanecem inalterados no total considerando um determinado espaço de tempo, mesmo que haja variações amplas relativas à atividade ou volume total (HORNGREN; DATAR; FOSTER, 2004). Desse modo, os custos fixos tendem à inércia, não acompanhando as oscilações da produção ou prestação de serviços. Por outro lado, se classificam como variáveis e são proporcionais ao nível da atividade, sendo o custo total majorado em decorrência do aumento da atividade, uma vez que ocorre somente quando a atividade ou produção é realizada (LEONE, 2008). Logo, o conhecimento sobre os custos, bem como sobre seu comportamento, pode auxiliar o tomador de decisão, o que implicará numa gestão de recursos mais eficiente.

Para melhor alocação dos custos aos produtos ou serviços é necessário um método de custeio que satisfaça à necessidade informacional do gestor e sejam fidedignos à realidade da organização. Esses métodos atuam no provimento de diversas informações, tanto na apuração dos custos incorridos na produção ou prestação de serviços, quanto na tomada de decisão de cunho gerencial e financeiro. Desta forma, destacam-se os principais métodos de custeio, sendo eles, Custeio por Absorção, Custeio Variável e Custeio Baseado em Atividades.

O custeio por absorção é o mais tradicional e aceito na contabilidade no Brasil, definido por Leone (2008, p. 242) como "aquele que faz debitar ao custo dos produtos todos os custos da área de fabricação, sejam esses custos definidos como custos diretos ou indiretos, fixos ou variáveis, de estrutura ou operacionais". Este é o método derivado da aplicação dos Princípios de Contabilidade Geralmente Aceitos, consistindo na apropriação de todos os custos de produção aos produtos, assim, todos os gastos incorridos serão distribuídos para todos os produtos e serviços realizados (MARTINS, 2010).

O custeio por absorção tem como uma das principais desvantagens o rateio dos custos indiretos, que algumas vezes é feito de forma arbitrária. Outro ponto diz respeito à departamentalização, a qual pode influenciar no resultado, caso opte por seu uso ou não. Contudo no estudo de Abbas, Gonçalves e Leoncine (2012), evidenciou-se que o custeio por absorção apresenta vantagens. Sendo que, além de aceito pela legislação, ele aloca tanto custos diretos quanto indiretos e é menos dispendiosa sua implementação.

Além do Custeio por Absorção, o Custeio Variável se faz opção. No entanto, estes não são admitidos pela legislação contábil e fiscal. Assim, é reconhecido que o "custeio variável é um método de custeio em que apenas os custos de materiais diretos são incluídos como custos do produto" (HORNGREN; DATAR; FOSTER, 2004, p. 277). Em síntese, custeio variável é aquele que considera os custos variáveis, devendo os demais serem considerados ao final como gastos do período.

O Custeio Baseado em Atividades, também chamado ABC (Activity-Based Costing), "é o método de custeio que procura reduzir sensivelmente as distorções provocadas pelo rateio dos custos indiretos" (MARTINS, 2010, p. 87). Ressalta-se que "o sistema ABC calcula os custos das atividades e atribui custos para os objetos de custos, como produtos ou serviços com base nas atividades necessárias para produzir cada produto ou serviço." (HORNGREN; DATAR; FOSTER, 2004, p. 131).

O método $\mathrm{ABC}$ se concentra, basicamente, na distribuição de custos considerados indiretos. Desta forma, procura-se identificar as atividades mais relevantes seguido de diversos outros detalhamentos, o que torna este método muito dispendioso, tanto na sua implantação, quanto na sua manutenção, embora sua forma seja bem vista na produção e prestação de serviços, dado seu nível de detalhamento. 
Diante do exposto, verifica-se que a melhor e mais viável opção para a alocação de custos no âmbito de prestação de serviços de OTS é custeio por absorção, que será utilizado neste trabalho.

\section{Metodologia}

Trata-se de uma pesquisa ação, com abordagem qualitativa e quantitativa, realizada em uma Instituição de Longa Permanência de Idosos (ILPI). A pesquisa ação representa "[...] enquanto técnica de pesquisa, cuja capacidade de superar impasses entre a teoria e a prática, por meio da interação e exploração de ambas é capaz de formar soluções para os ambientes organizacionais" (SOARES et al., 2009, p. 124). Para Gil (2008), a pesquisa ação se caracteriza pelo envolvimento do pesquisador e do pesquisado no processo de pesquisa, nela o observador e seus instrumentos desempenham papel ativo na coleta, análise e interpretação dos dados.

Já em relação à técnica, foi utilizada a pesquisa documental descrita por Marconi e Lakatos (2003), sendo esta uma fonte de coleta de dados restrita a documentos, escritos ou não, constituído as chamadas fontes primárias. A abordagem foi quali-quanti, pois tratou-se de uma análise de caráter qualitativa, incluindo acompanhamento das rotinas e realização de conversas informais, dentre outras provenientes da pesquisa ação. No que se refere a quantitativo justifica-se pelo uso de dados contidos em documentos observados.

Em um breve levantamento junto à prefeitura municipal, foi inicialmente percebida a existência de cinco entidades sem fins lucrativos na cidade de Rio Paranaíba/MG, sendo que uma delas chamou a atenção pela relevância humanitária e social e por estar passando por dificuldades financeiras. Assim, escolheu-se a "Casa de Repouso Confrade Antônio do Carmo Pimenta", que possui 41 internos, sendo 40 idosos e um portador de necessidades especiais, contando com 15 funcionários.

A Casa de Repouso Confrade Antônio do Carmo Pimenta, localizada no município de Rio Paranaíba/MG, atua na prestação de serviços a idosos, sua administração fica a cargo dos chamados "vicentinos" que são membros voluntários de uma organização religiosa católica, Sociedade de São Vicente de Paulo, movimento este de caráter internacional, a qual promove assistência social a pessoas carentes.

Em março de 2018, a instituição contava com 41 internos, sendo 22 homens, com idades entre 37 e 92 anos; e 19 mulheres, entre 50 e 105 anos. São 15 funcionários que atuam na prestação de serviços aos idosos, onde estes ficam distribuídos em uma estrutura que contém uma sala na entrada, 21 quartos, sete banheiros, sendo um direcionado para os funcionários, sala de fisioterapia, depósito de material de limpeza, sala de alimentação para funcionários, dispensa, sala de reunião, dispensário, cômodo próximo ao dispensário, cozinha, ala de lavanderia e refeitório para internos.

Para execução dos trabalhos na instituição, a equipe responsável era composta por: quatro alunos de graduação em Ciências Contábeis, sendo um deles o bolsista responsável pela centralização e execução dos trabalhos e os demais atuando como voluntários para apoio; dois professores do curso de Ciências Contábeis, coordenadores do projeto.

A princípio, entre março e dezembro de 2017, foram realizadas diversas atividades na entidade, por meio de uma ação extensionista de assessoria financeira e gerencial, que tinha como objetivo promover a sustentabilidade financeira das entidades filantrópicas de Rio Paranaíba/MG. Por meio do gerenciamento, controle e transparência do fluxo de recurso das entidades. Posteriormente, após a execução dessas atividades e com a organização das informações da entidade, a partir de janeiro de 2018 foi realizado o levantamento de todos os dados utilizados neste estudo. Assim, para fins de estudo foram considerados os dados referentes ao $1^{\circ}$ trimestre de 2018.

Dessa forma, os dados quantitativos foram coletados na própria instituição além dos extraídos na contabilidade a qual é terceirizada, sendo eles referentes à entrada e saída de recursos financeiros, notas fiscais de compras, cupons fiscais, controle interno de medicamentos, além da DRE do período e dos relatórios de pagamento de funcionários. Foi realizado um acompanhamento e analisadas rotinas e fluxos de caixa e, buscando aperfeiçoamento e novas técnicas junto à literatura, no intuito de adaptálas conforme a necessidade da organização. Na sequência, foram analisadas as notas e cupons fiscais afim de categorizar os itens das compras e, ao final, investigou-se os resultados e as implicações dessa intervenção na entidade.

Por fim, destaca-se que, para fins desse estudo, o método escolhido para a apropriação de custos foi o custeio por absorção, em que são distribuídos todos os custos inerentes ao objeto de custeio. 
Ademais, através dos dados obtidos na entidade, foi possível identificar a existência de quatro departamentos, sendo um de apoio, intitulado de Administração, e três ligados diretamente com a prestação de serviços. Sendo eles: Cozinha, Lavanderia e Enfermaria, onde estão incluídos os dormitórios.

\section{Resultados e Discussão}

\section{Custo do Serviço Prestado}

Conforme as informações levantadas junto à entidade, foi possível constatar que o controle de custos é feito de forma precária, sendo realizada em alguns casos de maneira imprecisa e sem demais detalhes. O controle de estoque na maioria dos casos é feito por meio de observações dos funcionários ou mesmo simples anotações.

Quando era demandada, a apuração dos custos do serviço prestado por parte da entidade era precária, uma vez que, por limitação de conhecimento, era simplesmente levantado o gasto do mês e dividido pela quantidade de internos, gerando o custo por interno. No entanto, pelo fato de desconsiderar alguns aspectos inerentes à contabilidade de custos, os valores desse levantamento são considerados inadequados, o que faz com que a tomada de decisões fosse feita embasada em números incorretos.

No presente estudo, para que a alocação dos custos seja distribuída de maneira condizente à realidade da entidade, baseou-se na Resolução ${ }^{\circ}$ 283/2005 da ANVISA, para a distribuição dos custos pelos internos segundo seu grau de dependência, conforme Tabela 1.

Tabela 1 - Classificação dos Internos conforme Grau de Dependência por Autocuidados

\begin{tabular}{lllc}
\hline Grau de Dependência & Descrição & Classes de Internos & Qtd. \\
\hline Grau de Dependência I & Idosos Independentes & Independente \\
Grau de Dependência II & $\begin{array}{l}\text { Dependência em até 3 atividades de } \\
\text { autocuidado: para a vida diária, como }\end{array}$ & \\
& $\begin{array}{l}\text { locomoção, alimentação e higiene. } \\
\text { Dependência que requer } \\
\text { Grau de Dependência III }\end{array}$ & assistência em todas as atividades de & \\
& autocuidado para a vida diária. & Incapaz & 5 \\
\hline
\end{tabular}

Fonte: elaborado pelos autores conforme dados da pesquisa e Resolução ANVISA n 283/2005.

Em relação à alocação dos custos, propriamente dita, foram considerados três grupos para distribuição entre as classes supracitadas: (i) custos diretos, que são aqueles de fácil identificação e distribuição conforme a classe de idosos; (ii) custos indiretos, caracterizados como aqueles que, apesar de se relacionarem diretamente com as Classes de internos, não são de fácil atribuição às classes; e, (iii) custos departamentais, os quais fazem parte da prestação de serviço, no entanto, não há relação direta com os idosos, devendo seus valores serem rateados posteriormente às classes.

\section{Custos Diretos}

\section{a) Mão de obra direta e indireta}

A Tabela 2 representa o custo de mão-de-obra (MO) total dos departamentos do $1^{\circ}$ trimestre de 2018, sendo nela evidenciados os gastos com funcionários, juntamente com os encargos sociais e reflexos inerentes. No que se refere à classificação da mão de obra como direta ou indireta, considerou-se direta aquela à qual há contato direto com a classe de idosos, possibilitando sua distribuição, embora todos visem o melhor atendimento; já os departamentos de administração, cozinha e lavanderia, por não lidarem diretamente com os internos, foram considerados indiretos.

Os encargos sociais foram considerados os percentuais de 27,5\% a título de encargos previdenciários e $8 \%$ correspondem ao Fundo de Garantia por Tempo de Serviço (FGTS). Quanto ao $13^{\circ}$ salário e às férias, foi estimado em 3/12 da remuneração, uma vez que os cálculos se referem ao trimestre, sendo que para as férias foi acrescido o terço constitucional. O item férias pagas têm seus valores em virtude de funcionários que usufruíram dos seus direitos de férias, mas não foram considerados no item remuneração. No departamento de administração, devido ao fato do colaborador ter seu contrato sob 
regime de estágio, não há o pagamento de encargos sociais nem férias e $13^{\circ}$, uma vez que não recebe remuneração referente a estágio.

No setor de enfermaria, evidenciados na Tabela 3, parte do recurso humano pode ser alocado diretamente às Classes de internos, no caso dos cuidadores e técnicos em enfermagem. Outra parte refere-se ao custo de mão-de obra indireta, que serão mais a frente alocados no departamento de enfermaria.

A partir de informações conseguidas junto à instituição sobre as rotinas diárias de uma cuidadora, bem como o tempo dedicado ao cuidado de cada classe de idosos, foi elaborada a Tabela 4, com a alocação dos valores da mão-de-obra direta, composta por cuidador e técnica em enfermagem às Classes de internos.

Tabela 2- Custos relacionados à mão-de-obra da ILPI - jan-mar/2018

\begin{tabular}{lcccc}
\hline Descrição & Cozinha & Enfermaria & Lavanderia & Administração \\
\hline Funcionários & 3 & 8 & 3 & 1 \\
Remuneração & $7.308,02$ & $25.362,85$ & $7.998,64$ & $1.527,21$ \\
Férias+1/3 & $2.436,01$ & $8.454,28$ & $2.666,21$ & $\mathrm{~N} / \mathrm{A}$ \\
$13^{\circ}$ salário & $1.827,00$ & $6.340,71$ & $1.999,66$ & $\mathrm{~N} / \mathrm{A}$ \\
Encargos Sociais & $2.594,35$ & $9.003,81$ & $2.839,52$ & $\mathrm{~N} / \mathrm{A}$ \\
Vale & $1.565,29$ & $5.246,49$ & $1.565,29$ & $\mathrm{~N} / \mathrm{A}$ \\
Férias Pagas & $1.352,00$ & $\mathrm{~N} / \mathrm{A}$ & $1.429,51$ & $\mathrm{~N} / \mathrm{A}$ \\
Total & $17.082,67$ & $54.408,15$ & $18.498,84$ & $1.527,21$ \\
\hline
\end{tabular}

Fonte: elaborado pelos autores conforme dados da pesquisa.

Tabela 3 - Custos da mão-de-obra (MO) direta e indireta da Enfermaria - jan-mar/2018

\begin{tabular}{llc}
\hline Custo & \multicolumn{1}{c}{ Descrição } & Valor \\
\hline MO direita & Atendimento direto ao interno: cuidador de idosos e técnica em enfermagem & $39.316,86$ \\
MO indireta & Demais funções do departamento & $16.032,61$ \\
\hline
\end{tabular}

Fonte: elaborado pelos autores conforme dados da pesquisa.

Tabela 4 - Distribuição dos custos de mão-de-obra conforme dependência dos internos - jan-mar/2018

\begin{tabular}{lcccc}
\hline & Incapaz & Dependente & Independente & Total \\
\hline Média de tempo (\%) & $50 \%$ & $40 \%$ & $10 \%$ & $100 \%$ \\
Rateio & $19.658,43$ & $15.726,75$ & $3.931,69$ & $39.316,86$ \\
\hline
\end{tabular}

Fonte: elaborado pelos autores conforme dados da pesquisa.

Devido à classe "Incapaz" ter o maior nível de dependência, necessitando de auxílio em praticamente todas as atividades na vida cotidiana, como em banhos, alimentação, locomoção, dentre outras, foi atribuído maior percentual dos custos com mão-de-obra (50\%); seguido da classe "Dependente" (40\%), que possui menor dependência, mas maior número de membros e, por isso, requer atenção de mais funcionários; e o menor percentual destinado à classe de "Independente" $(10 \%)$, por estes requererem pouco ou nenhum apoio no cotidiano.

\section{b) Medicamentos diretos}

Após listar todos os medicamentos adquiridos no $1^{\circ}$ trimestre pela instituição, e ao tomar como base o controle de medicamentos por idoso, fornecido pela ILPI, foi elaborada a Tabela 5, que representa os custos totais, apurados de forma sintética.

Tabela 5 - Custos diretos de medicamentos, por grau de dependência - jan-mar/2018

\begin{tabular}{lcccc}
\hline & Incapaz & Dependente & Independente & Total \\
\hline Medicamentos diretos & 566,67 & $2.308,16$ & $1.115,95$ & $3.990,78$ \\
\hline
\end{tabular}

Fonte: elaborado pelos autores conforme dados da pesquisa. 
Os valores dos medicamentos diretos, sintetizados na Tabela 5, se fez possível em virtude da fácil identificação para a alocação às classes. O mesmo não ocorre tratando-se dos medicamentos indiretos, de uso comum, que mais adiante serão rateados.

Além desses, a entidade se utiliza de medicamentos fornecidos pelo poder público, os quais não serão tratados na pesquisa. Fato idêntico acontece com as fraldas geriátricas, também conseguidas através de programas governamentais. Diante do exposto, verifica-se que a manutenção dessas concessões pode influenciar diretamente na continuidade da prestação de serviço da organização, uma vez que representa uma considerável economia.

\section{Custos indiretos}

Na Tabela 6, foram representados os custos considerados indiretos em razão de ser dificultosa e talvez equivocada sua alocação direta. Assim, mesmo reconhecendo que poderiam ter outros critérios de rateio mais adequados, usou-se o rateio tomando como base o número de internos pertencente às classes.

Os custos inerentes à alimentação advêm das notas e cupons fiscais obtidos na contabilidade, analisados e discriminados os produtos que tinham relação com a alimentação, foram encontrados os valores apresentados na Tabela 6. É importante salientar que, devido às diversas doações de alimentos recebidos, conforme relatado pela entidade, este custo poderia ser ainda mais alto.

Tabela 6 - Ratei dos custos indiretos as classes, de acordo com o grau de dependência - jan-mar/2018

\begin{tabular}{lcccc}
\hline Custos indiretos das Classes de internos & Incapaz & Dependente & Independente & Total \\
\hline $\mathrm{N}^{\mathrm{o}}$ de idosos & 5 & 23 & 13 & 41 \\
Alimentação & $2.303,71$ & $10.597,09$ & $5.989,66$ & $18.890,46$ \\
Medicamentos indiretos & 936,91 & $4.309,80$ & $2.435,97$ & $7.682,69$ \\
CUSTO TOTAL & $3.240,63$ & $14.906,89$ & $8.425,63$ & $26.573,15$ \\
\hline
\end{tabular}

Fonte: elaborado pelos autores conforme dados da pesquisa.

\section{Custos departamentais}

Os custos dos departamentos foram atribuídos de maneira direta ou por meio de rateio. Assim, os custos diretamente relacionados aos departamentos foram alocados a eles, enquanto que os custos indiretos foram rateados e em seguida distribuídos às Classes de internos.

Os custos classificados como indiretos foram rateados aos departamentos conforme a proporcionalidade dos custos diretos departamentais, sendo os critérios de rateio demonstrados na Tabela 7.

Tabela 7- Critérios de rateio dos custos indiretos para os departamentos da ILPI - jan-mar/2018

\begin{tabular}{lcccc}
\hline \multirow{2}{*}{ Custos } & \multicolumn{4}{c}{ Departamentos } \\
\cline { 2 - 5 } & Cozinha & Enfermaria & Lavanderia & Administração \\
\hline Custos Indiretos & $27,55 \%$ & $28,12 \%$ & $26,01 \%$ & $18,32 \%$ \\
Dep. Administração & $33,73 \%$ & $34,43 \%$ & $31,84 \%$ & $\mathrm{~N} / \mathrm{A}$ \\
\hline
\end{tabular}

Fonte: elaborado pelos autores conforme dados da pesquisa.

Sabendo-se disso, os custos foram distribuídos conforme Tabela 9, sendo consideradas as informações contidas nos fluxos de caixa, na DRE do $1^{\circ}$ trimestre e nos dados extraídos de cupons e notas fiscais. No que se refere aos custos indiretos, estes foram rateados com base no percentual de participação dos custos diretos departamentais conforme mostrado na Tabela 7.

Por prestar serviços aos outros departamentos, o valor atribuído ao departamento de administração foi rateado aos outros, tendo como ponto de partida a proporção de custos diretos apresentada pela cozinha, enfermaria e lavanderia. 
Tabela 8 - Distribuição e rateio dos custos diretos e indiretos departamentais - jan-mar/2018

\begin{tabular}{|c|c|c|c|c|c|}
\hline \multirow{2}{*}{ DESCRIÇÃO } & \multicolumn{3}{|c|}{ Departamentos de Serviços } & \multirow{2}{*}{$\frac{\text { Dep. Apoio }}{\text { Administração }}$} & \multirow{2}{*}{$\begin{array}{c}\text { TOTAL } \\
R \$\end{array}$} \\
\hline & Cozinha & Enfermaria & Lavanderia & & \\
\hline \multicolumn{6}{|l|}{ Custos diretos } \\
\hline Honorários & - & - & - & $1.460,00$ & $1.460,00$ \\
\hline Materiais de Escritório & - & - & - & 194,93 & 194,93 \\
\hline Combustíveis e Lubrificantes & - & 452,68 & - & 452,68 & 905,35 \\
\hline Conservação Veículos & - & 465,00 & - & 465,00 & 930,00 \\
\hline Mão-de-Obra & $16.513,53$ & $16.032,61$ & $18.092,55$ & $1.527,21$ & $52.165,91$ \\
\hline Exames e Consultas & - & $2.260,00$ & - & - & $2.260,00$ \\
\hline Despesas Financeiras & - & - & - & 907,77 & 907,77 \\
\hline Materiais de Consumo & $1.198,01$ & $1.713,00$ & $1.260,69$ & - & $4.171,70$ \\
\hline Gás & $2.788,00$ & - & - & - & $2.788,00$ \\
\hline Telefone & - & - & - & 670,76 & 670,76 \\
\hline Eventos & - & - & - & $4.524,00$ & $4.524,00$ \\
\hline Conselho Lagoa Formosa & - & - & - & $3.430,70$ & $3.430,70$ \\
\hline Subtotal 1 (custos diretos) & $20.499,54$ & $20.923,29$ & $19.353,24$ & $13.633,05$ & $74.409,12$ \\
\hline \multicolumn{6}{|l|}{ Custos Indiretos } \\
\hline Água & $1.348,63$ & $1.376,50$ & $1.273,21$ & 896,89 & $4.895,24$ \\
\hline Conservação e Manutenção & 862,14 & 879,96 & 813,93 & 573,36 & $3.129,40$ \\
\hline Energia Elétrica & 623,26 & 636,14 & 588,40 & 414,49 & $2.262,29$ \\
\hline Materiais Limpeza & 287,55 & 293,49 & 271,47 & 191,23 & $1.043,74$ \\
\hline Tributos & 172,80 & 176,38 & 163,14 & 114,92 & 627,24 \\
\hline Materiais de Consumo & 348,59 & 355,79 & 329,09 & 231,82 & $1.265,30$ \\
\hline Subtotal 2 (custos indiretos) & $3.642,96$ & $3.718,27$ & $3.439,26$ & $2.422,72$ & $13.223,21$ \\
\hline TOTAL (custos diretos + indiretos) & $24.142,50$ & $24.641,56$ & $22.792,50$ & $16.055,77$ & $87.632,33$ \\
\hline Rateio do Dep. Apoio $(16.055,77)$ & $5.415,55$ & $5.527,49$ & $5.112,72$ & $\stackrel{\downarrow}{\longleftarrow}$ & - \\
\hline Total dos Departamentos & $29.558,06$ & $30.169,05$ & $27.905,22$ & - & $87.632,33$ \\
\hline
\end{tabular}

Fonte: elaborado pelos autores conforme dados da pesquisa.

Feito a distribuição dos valores referentes aos departamentos, o próximo passo consistiu na alocação desses às Classes de internos. Para este fim, o critério adotado foi a quantidade de idosos constantes em cada classe, justificado pelo fato de que, principalmente os departamentos cozinha e lavanderia, prestarem seus serviços de maneira uniforme. Assim sendo, a Tabela 9 apresenta os resultados desse rateio.

Por fim, mediante ao exposto, o total do custo da prestação de serviço se deu segundo a Tabela 10, onde são compiladas as informações e separadas conforme as classes de internos.

Como mostra a Tabela 11, o custo total do serviço prestado aos idosos no $1^{\circ}$ trimestre de 2018 foi cerca de $\mathrm{R} \$ 157.513,33$. Dos custos totais, cerca de $22 \%$ foi alocado à classe de "Incapazes", $52 \%$ à de "Dependentes" e 26 \% para a classe de "Independentes". No entanto, pode-se constatar que, apesar da menor representatividade no custo total, a classe de "Incapazes" obteve maior custo por idoso no trimestre ( $\mathrm{R} \$$ 6.830,52), a frente dos “Dependentes" ( $\mathrm{R} \$ 3.569,63)$ e "Independentes" (R\$ 3.173,78).

Analisando esses custos, nota-se que os departamentais predominam dentre os outros, tendo maior contribuição no custo total $(55,63 \%)$, bem como na classe de "Independentes" $(67,34 \%)$ e de "Dependentes" (59,88 \%), enquanto que na classe de "Incapazes", o custo de mão-de-obra direta é o mais representativo, com $57,56 \%$ dos custos, sendo os custos departamentais o segundo mais expressivo, contando com 24,96 \% em relação ao custo total.

A base para o rateio tem sua justificativa, dentre outras, nas singularidades apresentadas na prestação desse serviço em ILPI a idosos, uma vez que deve ser levado em consideração as peculiaridades de cada interno. Um exemplo disso é alto custo da classe de "Incapazes", pois necessitam de mais apoio e cuidados, mesmo estando em menor número em relação às demais.

Em suma, as informações expostas pelo presente estudo poderão auxiliar os gestores na tomada de decisão, trazendo a eles maior conhecimento sobre os custos do serviço prestado na ILPI. Com isso, este trabalho poderá ser utilizado em decisões como a admissão de novos internos ou uma possível redução de custos das classes, desde que não prejudique a qualidade do serviço oferecido. Do mesmo 
Tabela 9 - Rateio dos custos departamentais às classes de internos, conforme grau de dependência jan-mar/2018

\begin{tabular}{lccccc}
\hline \multirow{2}{*}{ Classes de internos } & \multirow{2}{*}{$\mathrm{N}^{\mathrm{o}}$} & \multicolumn{3}{c}{ Departamentos } & \multirow{2}{*}{ Total } \\
\cline { 3 - 5 } & & Cozinha & Enfermaria & Lavanderia & \\
\hline Incapaz & 5 & $3.604,64$ & $3.679,15$ & $3.403,08$ & $\mathbf{1 0 . 6 8 6 , 8 7}$ \\
Dependente & 23 & $16.581,35$ & $16.924,10$ & $15.654,15$ & $\mathbf{4 9 . 1 5 9 , 6 0}$ \\
Independentes & 13 & $9.372,07$ & $9.565,80$ & $8.848,00$ & $\mathbf{2 7 . 7 8 5 , 8 6}$ \\
Total & 41 & $29.558,06$ & $30.169,05$ & $27.905,22$ & $87.632,33$ \\
\hline
\end{tabular}

Fonte: elaborado pelos autores conforme dados da pesquisa.

Tabela 10 - Custo total do serviço prestado às classes de internos, conforme grau de dependência jan-mar/2018

\begin{tabular}{lccccc}
\hline \multirow{2}{*}{ Descrição } & \multicolumn{3}{c}{ Classes de internos } \\
\cline { 2 - 6 } & un. & Incapaz & Dependente & Independente & Total \\
\hline Medicamentos & $R \$$ & 566,67 & $2.308,16$ & $1.115,95$ & $3.990,78$ \\
& $\%$ & $1,66 \%$ & $2,81 \%$ & $2,70 \%$ & $2,53 \%$ \\
Mão-de-obra direta & $R \$$ & $19.658,43$ & $15.726,75$ & $3.931,69$ & $39.316,87$ \\
& $\%$ & $57,56 \%$ & $19,16 \%$ & $9,53 \%$ & $24,96 \%$ \\
Custos Indiretos & $R \$$ & $3.240,63$ & $14.906,89$ & $8.425,63$ & $26.573,15$ \\
& $\%$ & $9,49 \%$ & $18,16 \%$ & $20,42 \%$ & $16,87 \%$ \\
Custos Departamentais & $R \$$ & $10.686,89$ & $49.159,71$ & $27.785,92$ & $87.632,53$ \\
& $\%$ & $31,29 \%$ & $59,88 \%$ & $67,34 \%$ & $55,63 \%$ \\
Total & $R \$$ & $34.152,62$ & $82.101,51$ & $41.259,20$ & $157.513,33$ \\
Custo trimestral por interno & & $6.830,52$ & $3.569,63$ & $3.173,78$ & $1.057,93$ \\
Custo estimado mensal & & $2.276,84$ & $1.189,88$ & & \\
\hline
\end{tabular}

Fonte: elaborado pelos autores conforme dados da pesquisa.

modo, o uso dessas informações poderá valer como embasamento para a solicitação e arrecadação de novos recursos, visando um atendimento de qualidade aos usuários.

Faltou discutir os resultados do presente trabalho com a literatura sobre o assunto. Existem outros trabalhos que conseguiram reduzir custos? Em que a redução de custos implicou?

\section{Considerações Finais}

As organizações do terceiro setor desempenham importante papel na sociedade em geral. Nos últimos tempos, com o envelhecimento da população, entidades como as ILPI, que prestam atendimento aos idosos, devem estar preparadas para esse provável aumento dos usuários. Assim, a contabilidade deve desempenhar sua função, auxiliando os gestores no melhor gerenciamento dessas instituições.

Para o atendimento do objetivo do estudo, optou-se pelo método de custeio por absorção, em razão de ser mais simples sua implantação, se comparado aos outros métodos existentes. Após segregar os internos em classes, conforme a resolução 283/2005 da ANVISA foi feita a alocação dos custos do trimestre, o qual ficou evidenciado que o custo por idoso da classe de "Incapazes" é $115 \%$ maior do que a classe de "Independentes" e $91 \%$ mais elevado que a de "Dependentes". Todavia, em se tratando de valores dos custos totais, devido à quantidade de idosos em cada categoria, a classes de "Dependentes" tem maior representatividade, sendo $52 \%$ do custo total, seguido da classe de "Independentes" (26 \%) e da classe de "Incapazes" (22 \%).

Uma observação pertinente diz a respeito ao financiamento deste custo, uma vez que o menor valor de custo estimado unitário, pertencente à classe de "Independentes" (R\$ 1.057,93), é maior do que o valor do salário mínimo vigente em 2018 (R\$954,00), que é a base para o os valores dos aposentos arrecadados pela ILPI para manter a assistência aos idosos. Isso evidencia que, mesmo que haja receitas provenientes dos benefícios recebidos pelos idosos, a entidade é dependente também de outras receitas, tais como subsídios governamentais e doações diversas. 
Assim, a relevância deste trabalho esteve em contribuir com a gestão das ILPI, que evidenciando a importância da contabilidade de custos para suprimento das necessidades informacionais, auxiliando na tomada de decisão. Além disso, essa pesquisa pode servir de suporte na busca de recursos, uma vez que demonstra a importância de uma boa gestão dos recursos, frequentemente escassos nesses tipos de organizações.

Ao reconhecer a importância social dessas entidades, recomenda-se o estudo nesta área visando aperfeiçoar os sistemas de custos, para que possam auxiliar no controle e planejamento das organizações. Para futuras pesquisas, sugere-se a investigação da contribuição dos demais campos da contabilidade para outras entidades dessa mesma categoria.

\section{Agradecimentos}

Esse trabalho é dedicado a Ailton José da Rocha, Maria Eni da Silva Rocha e Luana Vanessa Rocha.

Agradecimento à Universidade Federal de Viçosa, que possibilitou a realização do projeto “Assessoria financeira e gerencial a entidades filantrópicas de Rio Paranaíba/MG" (PRJ-016/2017), pela concessão de bolsa de Extensão Universitária.

Agradecimento também à Casa de Repouso Confrade Antônio do Carmo Pimenta pela autorização ao desenvolvimento do projeto na instituição.

\section{Referências}

ABBAS, K.; GONÇALVES, M. N.; LEONCINE, M. Os métodos de custeio: vantagens, desvantagens e sua aplicabilidade nos diversos tipos de organizações apresentadas pela literatura. ConTexto, Porto Alegre, v. 12, n. 22, p. 145-159.

BRASIL. Lei $n^{\circ} 10741$, de $1^{0}$ de outubro de 2003. Dispõe sobre o Estatuto do Idoso e dá outras providências. Disponível em: <http://www.planalto.gov.br/ccivil_03/leis/2003/L10.741.htm>. Acesso em 11 jun. 2018.

BRASIL. Resolução RDC $n^{0}$ 283, de 26 de setembro de 2005. Aprova o Regulamento Técnico que define normas de funcionamento para as Instituições de Longa Permanência para Idosos. Órgão emissor ANVISA - Agência Nacional de Vigilância Sanitária. Disponível em: <http://sbgg.org.br/ wp-content/uploads/2014/10/rdc-283-2005.pdf>. Acesso em: 22 jun. 2017.

CAMARANO, A. A.; KANSO, S. As instituições de longa permanência para idosos no Brasil. Rev. bras. estud. popul., São Paulo, v. 27, n. 1, p. 232-235, junho 2010.

GIL, Antônio Carlos. Métodos e técnicas de pesquisa social. 6a ed. São Paulo: Atlas, 2008.

HORNGREN, Charles T.; DATAR, Srikan M; FOSTER, George. Contabilidade de custos: uma abordagem gerencial. 11. ed. São Paulo: Prentice Hall, 2004. 526 p.

IBGE. INSTITUTO BRASILEIRO DE GEOGRAFIA E ESTATISTICA. As Entidades de assistência social privada sem fins lucrativos no Brasil: 2014-2015: unidades de prestação de serviços socioassistenciais / IBGE, Coordenação de População e Indicadores Sociais. - Rio de Janeiro : IBGE, 2015. 60 p. Disponível em: <http://biblioteca.ibge.gov.br/visualizacao/livros/liv94686.pdf>. Acesso em 22 jun. 2017.

LEONE, George S. G. Curso de Contabilidade de Custos. $3^{\text {a }}$ ed. São Paulo: Atlas, 2008.

MARCONI, M. A.; LAKATOS, E. M. Fundamentos de Metodologia Científica. 5a. ed. São Paulo: Atlas, 2003.

MÁRIO, P., ALVES, A., CARMO, J., SILVA, A., JUPETIPE, F. A Utilização de Instrumentos de Contabilidade Gerencial em Entidades do Terceiro Setor. SOCIEDADE, CONTABILIDADE E GESTÃO, 8, jun. 2013. Disponível em: <http://atena.org.br/revista/ojs-2.2.3-08/index.php/ufrj/ article/view/1645/1466> Acesso em: 24 jun. 2017

MARTINS, Eliseu. Contabilidade de Custos. 10ª ed. São Paulo: Atlas, 2010. 
MEDEIROS, P. A.; FORTUNATO, A. R.; VISCARDI, A. A. F.; SPERANDIO, F. F.; MAZO, G. Z. Instrumentos desenvolvidos para o gerenciamento e cuidado de idosos em instituições de longa permanência: uma revisão sistemática. Ciência E Saúde Coletiva, v. 21, n. 11, p. 3597-3610, 2016.

PAULA, C. L. S.; MÁRIO, P. C. Nível de evidenciação contábil das fundações privadas do município de Belo Horizonte: uma análise das entidades de educação e pesquisa. Dissertação (Mestrado em Ciências Contábeis). Universidade Federal de Minas Gerais. Belo Horizonte, 2011.

PEREIRA, Milton et al. Gestão para organizações não governamentais. Florianópolis: Editora Tribo da Ilha, 2013. 226 p. Disponível em: <http://www.institutofonte.org.br/sites/default/files/Livro Gestão Para Organizações Não Governamentais - 2013.pdf> . Acesso em: 17 jun. 2017.

PEREIRA, Raquel da Silva et al. Especificidades da Gestão no Terceiro Setor. Organizações em Contexto, São Bernardo do Campo, v. 9, n. 18, p. 167-195, jul.-dez. 2013.

LIMA POLLO, S. H.; ASSIS, M. Instituições de Longa Permanência para Idosos - ILPIS: desafios e alternativas no município do Rio de Janeiro. Revista Brasileira de Geriatria e Gerontologia. v. 11, n. 1, p. 29-43, 2008.

ROQUETE, Fátima Ferreira; BATISTA, Carolina Campos Ricci Frá; ARANTES, Rodrigo Caetano. Demandas assistenciais e gerenciais das instituições de longa permanência para idosos: uma revisão integrativa (2004-2014). Revista Brasileira de Geriatria e Gerontologia, Rio de Janeiro, v. 20, n. 2, p. 286-299.

SANTOS, C. A. Práticas de contabilidade das organizações sem fins lucrativos de Curitiba. Dissertação (Mestrado em Contabilidade). Universidade Federal do Paraná. Curitiba, 2010.

SANTOS, N. O.; BEUTER, M.; GIRARDON-PERLINI; N. M. O.; PASKULIN, L. M. G.; LEITE, M. T.; BUDÓ, M. L. D. Percepção de Trabalhadores de uma Instituição de Longa Permanência para Idosos Acerca da Família. Texto E Contexto Enfermagem, v. 23, n. 4, p. 971-978, 2014.

SANTOS, M. R. C.; LAUREANO, R. M. S.; MACHADO, M. J. Contabilidade de gestão no terceiro setor: estudo empírico em instituições particulares de solidariedade social. TMStudies, Faro, v. 10, n. Especial, p. 79-87, dez. 2014.

SANTOS, S. X. Organização do Terceiro Setor. Natal: Edunp, 2012.

SCHEUER, I.; BASSO, L.; DIDONÉ, M. L. Fluxo de caixa para entidade sem fins lucrativos. In: Jornada de Extensão, XVII., 2016, Salão do conhecimento: ciência alimentando o Brasil. Unijuí, 2016. p. 1 - 6. Relatório técnico científico. Disponível em: <https://www.publicacoeseventos. unijui.edu.br/ index.php/salaoconhecimento/article/viewFile/6319/5097>. Acesso em: 25 jun. 2017.

SOARES, A. C.; MELO, M. C. Desafios gerenciais de organizações do terceiro setor de Belo Horizonte: técnicos, políticos, críticos e praxeológicos. Revista Gestão e Planejamento. v. 10. n. 1, p. 38-52, jan/jun, 2009.

SOARES, M.; PATON, C.; SANTOS, A. F.; BEZERRA, F. A. Uma discussão sobre a viabilidade da Pesquisa-Ação na contabilidade. Revista de Contabilidade e Organizações, São Paulo, v. 3, n. 7, p. 109126, 2009.

TENÓRIO, F. G. Gestão de ONGs: principais funções gerenciais. 11. ed. Rio de Janeiro: Editora FGV, 2009.

TOZZI, J. A. Gestão financeira e orçamentária no terceiro setor. Pensamento E Realidade, v. 29, n. 2, p. 44-62, 2014.

VOESE, Simone Bernardes; REPTCZUK, Roseli Maria. Características e peculiaridades das entidades do terceiro setor. Contexto, Porto Alegre, v. 11, n. 19, p. 31-42, 2011.

Data de submissão: 26/10/2018. Data de aceite: 7/2/2019. 


\section{Homenagem póstuma}

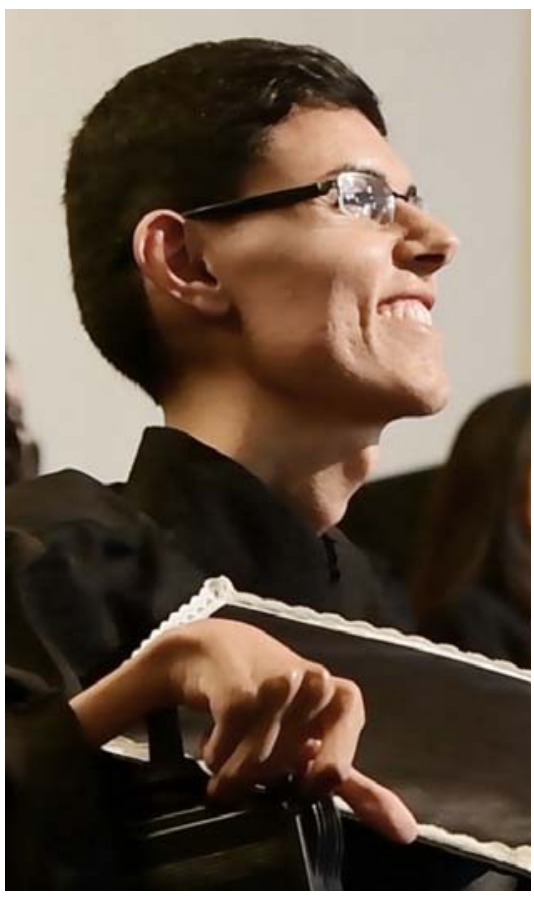

Lucas Alexandre Rocha foi aluno do curso de Ciências Contábeis da Universidade Federal de Viçosa, campus Rio Paranaíba, e bolsista do projeto de extensão "Assessoria financeira e gerencial a entidades filantrópicas de Rio Paranaíba/MG", que gerou esse trabalho.

Lucas foi, de fato, uma pessoa especial! Sempre com um sorriso no rosto, conduziu as atividades do ensino e da extensão com muita competência, tendo concluído esse ciclo em 3 de agosto de 2018, quando graduou-se Contador.

Premiando todo a sua dedicação para com o projeto, tornando público os resultados de uma extensão universitária, foi submetido o artigo fruto desse trabalho no dia 26 de outubro de 2018. No entanto, o que não se esperava é que, por uma triste obra do destino, cinco dias mais tarde se dava o encerramento de sua iluminada estadia nesse plano.

Portanto, fica aqui a homenagem a esse ser humano brilhante e o agradecimento à sua família por nos proporcionar tê-lo conhecido.

Muito obrigado por tudo, Lucas! 